\title{
PENGARUH DISCOVERY LEARNING BERBANTUAN PAKET PROGRAM SIMULASI PHET TERHADAP PRESTASI BELAJAR FISIKA
}

\section{THE EFFECT OF DISCOVERY LEARNING MODEL WITH PHET SIMULATION AID TO STUDENTS' PHYSICS LEARNING ACHIEVEMENT}

\author{
Agus Hariyanto \\ UPTD SMAN 1 Kertosono \\ JL. Panglima Sudirman No 10 Kertosono Kabupaten Nganjuk \\ e-mail: hariyanto.agoes@gmail.com
}

Naskah diterima tanggal: 10-9-2016, Direvisi akhir tanggal: 15-12-2016, disetujui tanggal: 30-12-2016

\begin{abstract}
Discovery learning is designed with the aim that students can find their own concepts on what they study and work effectively in a group. The purpose of this study was to determine the effect of discovery learning PhET aided simulation program on learning achievement compare to the discovery learning. The study used a quasi-experiment with 2 $\times 2$ factorial design. The technique of data collection began with the test of prior ability of students and at the end of the study they were given physics learning achievement tests. The technique of data analysis using ANOVA test two paths. The results show that the physics achievement of students studying by means of discovery learning with PhET simulation aid was better than those who studied with discovery learning. In conclusion, discovery learning with PhET simulation aid affects positively towards students' learning achievement.
\end{abstract}

Keywords: discovery learning, PhET simulation, physics learning achievement

\begin{abstract}
Abstrak: Discovery learning dirancang dengan tujuan agar siswa dapat menemukan sendiri konsep yang dipelajari dan bekerja secara efektif dalam kelompok. Tujuan penelitian ini adalah untuk mengetahui pengaruh discovery learning berbantuan program simulasi PhET terhadap prestasi belajar dibandingkan dengan discovery learning. Penelitian menggunakan quasi experiments dengan desain faktorial $2 \times 2$. Teknik pengumpulan data kemampuan awal dengan melakukan tes kemampuan awal pada awal penelitian dan pada akhir penelitian diberikan tes prestasi belajar fisika. Teknik analsis data menggunakan uji anava dua jalur. Hasil uji Anava dua jalur menunjukkan bahwa prestasi belajar fisika kelompok siswa yang belajar melalui discovery learning berbantuan paket program simulasi PhET lebih tinggi daripada kelompok siswa yang belajar melalui discovery learning. Dengan demikian, discovery learning berbantuan program simulasi PhET mempengaruhi secara positif prestasi belajar siswa.
\end{abstract}

Kata kunci: discovery learning, simulasi PhET, prestasi belajar fisika

\section{PENDAHULUAN}

Kerangka kompetensi abad ke-21 menghendaki pembelajaran yang menuntun siswa untuk berkemampuan kreatif, inovatif, berpikir kritis dalam menyelesaikan masalah, dan komunikatif dan kolaboratif. Siswa juga harus sadar dan memiliki kemampuan untuk memanfaatkan teknologi informasi, media, dan teknologi sesuai dengan perkembangan zaman.

Salah satu upaya nyata pemerintah guna menghadapi kerangka kompetensi abad ke-21 adalah dengan mengubah persepsi mengenai pembelajaran. Pemerintah menyusun kurikulum baru yakni Kurikulum 2013 yang disesuaikan 
dengan kebutuhan abad ke-21. Kurikulum 2013 bertujuan untuk mempersiapkan manusia Indonesia agar memiliki kemampuan hidup sebagai pribadi dan warga negara yang beriman, produktif, kreatif, inovatif, dan afektif serta mampu berkontribusi pada kehidupan bermasyarakat, berbangsa, bernegara, dan peradaban dunia (Peraturan Menteri Pendidikan dan Kebudayaan RI No. 70 tahun, 2013) melalui pembelajaran yang menekankan pendekatan saintifik (scientific approach).

Keberhasilan atau kegagalan suatu proses pembelajaran dapat dilihat melalui prestasi belajar yang diperoleh siswa (Amiroh, 2014). Prestasi belajar merupakan bagian yang sangat penting dan merupakan hasil akhir yang dicapai setelah melalui proses pembelajaran (Rahma, 2013). Keberhasilan yang dicapai siswa dalam melakukan kegiatan belajar merupakan sebuah bukti prestasi belajar.

Konsep-konsep fisika dalam bidang kelistrikan banyak yang bersifat abstrak, serta sulit untuk dipelajari secara nyata (Tambade \& Wagh, 2011). Berdasarkan wawancara dengan siswa, didapatkan bahwa siswa mengalami kendala ketika mempelajari karakteristik rangkaian seri dan paralel. Di samping itu siswa kesulitan menentukan besar dan arah arus dalam rangkaian tertutup. Pada dasarnya, kendalakendala dalam mempelajari listrik arus searah tidak akan terjadi, jika siswa diberikan analogi dan penggunaan model yang tepat mengenai konsep listrik arus searah (Mursalin, 2012).

Mengatasi kesulitan siswa dalam memahami konsep listrik arus searah dapat diatasi dengan multimedia. Multimedia merupakan alat yang dapat menciptakan presentasi dinamis dan interaktif yang mengkombinasikan teks, grafik, animasi, audio dan video (Asthana, 2010) serta bersifat konstruktivis, memberikan umpan baik, dan menyediakan tempat kerja (Finkelstein, 2006). Multimedia interaktif cocok untuk mengatasi kesulitan siswa dalam mengeksplorasi kemampuan mengungkapkan ide mengenai konsep yang dipelajari (Podolefsky, Perkins, \& Adams, 2010).
Pembelajaran fisika di sekolah hendaknya menekankan pada pemberian pengalaman langsung untuk mengembangkan kompetensi agar mengembangkan ide-ide dalam kehidupan nyata. Siswa diharapkan menemukan pengetahuan dan keterampilan bukan hanya mengingat seperangkat fakta tetapi juga menemukan sendiri dengan cara observasi, bertanya, mengajukan hipotesa, mengumpulkan data, dan mengambil kesimpulan (NSTA, 2004). Keaktifan dan kemampuan siswa dalam menemukan konsep haruslah dilatih agar proses pembelajaran dapat berjalan dengan baik (Wenning, 2011).

Kesulitan yang dihadapi siswa dalam melatih keaktivan dan menemukan sendiri konsep yang dipelajari dikarenakan pembelajaran yang masih berpusat pada guru (Klahr \& Nigam, 2004). Kegiatan yang berpusat pada guru kurang mendukung pengembangan pengetahuan dan keterampilan peserta didik dalam penguasaan konsep fisika (Crebert, dkk, 2011). Guru tidak hanya mentransfer pengetahuan kepada siswa tetapi juga dapat memfasilitasi siswa dalam mengkonstruksi pengetahuannya (AAPT, 2009). Aktivitas pembelajaran tidak hanya difokuskan pada upaya mendapatkan penguasaan konsep saja, melainkan juga siswa berpartisipasi aktif dalam pembelajaran melalui kelompok untuk mencari informasi, membahas pertanyaan, dan mencapai informasi melalui percobaan (Balim, 2009).

Upaya meningkatkan keaktifan siswa dalam menemukan sendiri konsep yang dipelajari dan prestasi belajar diperlukan metode pembelajaran yang inovatif. Salah satu alternatif pembelajaran adalah discovery learning. Beberapa penelitian mengenai penerapan discovery learning dalam pembelajaran menyatakan bahwa discovery learning dapat meningkatkan kemampuan siswa mengkonstruksi untuk membangun pengetahuannya sendiri dibandingkan dengan pembelajaran konvensional (Klahr \& Nigam, 2004; Putrayasa, dkk., 2014; Indarti, dkk., 2014). Di samping itu, siswa memiliki kemampuan untuk secara aktif mencari, mengolah, meng- 
konstruksi, dan mencari sendiri makna sesuatu yang dipelajari (Nisa' \& Suliyanah, 2014).

Masih ditemukan adanya kelemahan dalam pelaksanaan discovery learning dalam pembelajaran Fisika (Kartikowati, 2011). Selain itu, discovery learning dapat membebani siswa karena membutuhkan waktu yang lama dalam penerapannya pada tahap data collection (Rohim, dkk., 2012).

Usaha perbaikan perlu dilakukan untuk mengatasi kendala yang dihadapi dalam discovery learning. Untuk mengurangi kelemahan pada tahap problem statement diperlukan menghadirkan pertanyaan atau masalah untuk mendorong siswa untuk membuat tebakan intuitif (Schunk, 2008). Pertanyaan tersebut dapat diakomodasi dalam multimedia yang telah dipersiapkan oleh guru sebelum pembelajaran dimulai (Cohen, 2008). Waktu yang lama pada tahap data collection dapat diatasi dengan menghadirkan multimedia interaktif yang dapat mempersingkat waktu dalam melakukan percobaan (Mubarrok \& Mulyaningsih, 2014). Selanjutnya melalui ilustrasi-ilustrasi yang diberikan dapat menciptakan suasana yang kondusif agar siswa aktif mengemukakan ide-idenya (Cohen, 2008).

Ilustrasi yang dihadirkan guru haruslah menarik perhatian siswa (Podolefsky, Moore, \& Perkins, 2012). Memahami materi fisika diperlukan bantuan simulasi komputer agar siswa tertarik dengan yang akan dipelajari (Adegoke, 2010). Program simulasi komputer sangat cocok dalam penerapan discovery learning (Jong, \& Joolingen, 1998). Simulasi berbagai macam fenomena fisika secara audio dan visual menyerupai aslinya dapat dihadirkan ke hadapan siswa dalam bentuk program komputer (Chini, dkk., 2012). Dengan simulasi komputer dapat ditampilkan gambar yang menyerupai aslinya dengan menggunakan perangkat lunak grafis 3D (Martinez, dkk., 2011).

Kemajuan teknologi dan informasi berdampak pada perkembangan media visual yang pada akhirnya efektif membantu kegiatan pembelajaran (Swaak, dkk, 2004). Komputer dapat membantu siswa memaksimalkan waktu pembelajaran dalam memahami dan menumbuhkan motivasi siswa dalam belajar fisika (Sadaghiani, 2011). Adanya komputer berdampak terhadap keaktifan siswa dalam pembelajaran (Armstrong \& Retterer, 2008), tambahan/penguatan pengetahuan terhadap informasi dan kemampuan berpartisipasi (Hrastinski \& Monstad, 2013) dan peningkatan pengguna situs fisika di internet (Squire \& Dikkers, 2012).

Program simulasi PhET merupakan media simulasi interaktif menyenangkan berbasis penemuan berupa software dan dapat digunakan untuk memperjelas konsep-konsep fisis atau fenomena yang telah dipraktikumkan (Mubarrok \& Mulyaningsih, 2014). Pembelajaran dengan menggunakan simulasi PhET membuat siswa tertarik dan semangat melakukan praktikum sehingga menuntaskan hasil belajar siswa (Prihatiningtyas, dkk., 2013). Di samping itu pembelajaran fisika dengan menggunakan multimedia interaktif PhET memberikan hasil belajar lebih baik daripada kelas yang hanya menggunakan praktikum saja tanpa disertai penggunaan media PhET (Mubarrok \& Mulyaningsih, 2014).

Pembelajaran yang mengolaborasikan pembelajaran discovery learning dan paket program simulasi PhET diharapkan menciptakan suasana pembelajaran yang menarik, membuat siswa lebih aktif, dan meningkatkan motivasi untuk memahami ilmu fisika sehingga membantu siswa dalam meningkatkan prestasi belajar fisika. Tahapan discovery learning yang disisipkan paket program simulasi PhET yaitu tahapan stimulation, problem statement, dan data collection. Tujuan penggunaan paket program simulasi PhET untuk mengatasi kelemahan discovery learning.

Penyajian paket program simulasi $P h E T$ pada tahap stimulation bertujuan untuk memberikan fenomena kepada siswa lebih detail daripada menggunakan peralatan laboratorium. Sehingga diharapkan siswa mampu mengamati fenomena dengan jelas disertai dengan simulasi dan 
memotivasi siswa untuk melangkah ke tahap problem statement. Penggunaan paket program simulasi PhET lebih praktis digunakan untuk mengganti peralatan nyata tentang rangkaian listrik sederhana arus searah (Finkelstein, 2006). Sedangkan penyajian fenomena dengan peralatan laboratorium, siswa hanya dapat melihat fenomena secara dangkal tanpa mengetahui penjelasan secara mikroskopis yang terjadi dalam fenomena.

Problem statement yang dirumuskan oleh siswa yang belajar menggunakan paket program simulasi PhET lebih mendalam daripada problem statement yang dirumuskan oleh siswa yang belajar menggunakan peralatan laboratorium. Simulasi PhET juga mampu menghubungkan gagasan yang dimiliki siswa dengan kehidupan nyata yang terjadi dalam kehidupan sehari-hari dan menggunakan fenomena sains dalam simulasi PhET untuk memahami dunia nyata (Finkelstein, 2006). Siswa yang belajar menggunakan paket program simulasi PhET mengumpulkan data (data collection) lebih lengkap dan mendekati konsep fisika karena paket program simulasi PhET dibuat dengan mengabaikan hal-hal mempengaruhi hasil pengamatan, misalnya hambatan dalam baterai, hambatan pada kawat, hambatan dalam lampu atau ketelitian dalam penggunaan alat ukur sehingga siswa mampu menyimpulkan hasil percobaan secara mandiri dan benar (Adams, 2010). Siswa yang belajar menggunakan peralatan laboratorium akan kesulitan dalam pengumpulan data karena tergantung pada kondisi dan tingkat ketelitian alat sehingga data yang diperoleh memerlukan analisis yang lebih mendalam agar mendekati konsep yang ada.

Melalui pembelajaran ini, siswa bekerja secara kelompok dengan menggunakan lembar kerja dengan paket program simulasi PhET. Adanya LKS ini dapat memberikan peranan kepada siswa dalam membantu menuangkan ideidenya dan dapat memberikan umpan balik yang tepat (Alfieri, 2011). Siswa berinteraksi dengan siswa lain untuk mencapai tujuan yang akan dicapai dalam kelompok. Kerja sama dalam menyelesaikan masalah memberikan kesempatan kepada siswa untuk mencapai pengetahuan yang baru yang tidak mereka capai ketika bekerja sendiri. Melalui discovery learning ini siswa dituntut berpartisipasi aktif mencari informasi dalam kelompok (Balim, 2009). Informasi digunakan untuk menuntun siswa dalam mencapai konsep yang diinginkan (Cohen, 2008).

Siswa yang belajar melalui discovery learning berbantuan paket program simulasi PhET lebih cepat menyelesaikan masalah dalam kelompoknya. Penggunaan paket program simulasi PhET lebih praktis digunakan untuk mengganti peralatan nyata tentang rangkaian listrik sederhana DC (Finkelstein, 2006) dan siswa mampu menyimpulkan hasil percobaan secara mandiri (Adams, 2010). Simulasi PhET juga mampu menghubungkan gagasan yang dimiliki siswa dengan kehidupan nyata yang terjadi dalam kehidupan sehari-hari dan menggunakan fenomena sains dalam simulasi PhET untuk memahami dunia nyata (Finkelstein, 2006).

Penggunaan paket program simulasi PhET mampu menuntaskan hasil belajar fisika (Prihartiningsih, dkk., 2013), pemahaman konsep fisika (McKagan, dkk., 2008) dan dapat memberikan kesempatan kepada siswa untuk memperoleh pemahaman yang baik mengenai konsep yang akan dipelajari (Swaak \& de Jong, 2004). Dengan demikian, siswa yang belajar melalui discovery learning berbantuan paket program simulasi PhET akan memiliki prestasi belajar lebih tinggi daripada siswa yang belajar menggunakan discovery learning saja. Penguasaan konsep siswa terbentuk sebagai hasil modifikasi maupun penguatan terhadap konsep yang sudah dimiliki siswa (Azis, 2013).

Tujuan penelitian ini yaitu untuk mengetahui pengaruh discovery learning berbantuan paket program simulasi $P h E T$ terhadap prestasi belajar dibandingkan dengan discovery learning tanpa program simulasi PhET.

Hasil penelitian ini diharapkan dapat memberikan manfaat sebagai berikut; 1) Bagi siswa, sebagai variasi dalam belajar untuk melatih 
kemampuan menemukan dan meyelidiki sendiri informasi, sehingga dapat meningkatkan prestasi belajar, 2) Bagi pendidik, sebagai referensi dan tambahan wawasan dalam melaksanakan pembelajaran agar lebih bervariasi, menyenangkan dan memberdayakan siswa untuk berpartisipasi aktif sehingga pembelajaran menjadi lebih bermakna, 3) Bagi sekolah, hasil penelitian ini dapat memberikan sumbangan dalam usaha meningkatkan kualitas pembelajaran di sekolah dalam upaya meningkatkan hasil belajar siswa, 4) Bagi peneliti lain, sebagai sumber informasi dan referensi dalam usaha mengembangkan teori pembelajaran atau ilmu pengetahuan menjadi lebih luas lagi.

\section{METODE}

Jenis penelitian ini adalah quasi experiment dengan desain factorial $2 \times 2$ seperti ditunjukkan pada Tabel 1.

Sampel dipilih dengan teknik cluster sampling. Sampel penelitian yaitu kelas $X$ yang tersebar di tiga sekolah yaitu, SMAN 1 Kertosono, SMAN 1 Patianrowo, dan SMAN 1 Ngronggot. Penelitian ini dilaksanakan bulan Maret 2015-April 2016. Instrumen penelitian yang digunakan dalam penelitian ini terdiri atas instrumen perlakuan dan instrumen pengukuran. Instrumen pelakuan terdiri dari silabus, Rencana Pelaksanaan Pembelajaran (RPP) yang menggunakan sintaks pembelajaran discovery

Tabel 1. Model Rancangan Pendekatan

\begin{tabular}{|c|c|c|}
\hline \multirow[t]{2}{*}{$\begin{array}{l}\text { Prestasi Belajar } \\
\text { (B) }\end{array}$} & \multicolumn{2}{|c|}{$\begin{array}{l}\text { Pembelajaran } \\
\text { (A) }\end{array}$} \\
\hline & $\begin{array}{l}\text { discovery } \\
\text { learning } \\
+ \text { PhET } \\
\left(\mathrm{A}_{1}\right)\end{array}$ & $\begin{array}{l}\text { discovery } \\
\text { learning } \\
\left(\mathrm{A}_{2}\right)\end{array}$ \\
\hline $\begin{array}{l}\text { Kemampuan }\left(\mathrm{B}_{1}\right) \\
\text { awal tinggi }\end{array}$ & $\mathrm{A}_{1} \mathrm{~B}_{1}$ & $\mathrm{~A}_{2} \mathrm{~B}_{1}$ \\
\hline $\begin{array}{l}\text { Kemampuan } \quad\left(B_{2}\right) \\
\text { awal rendah }\end{array}$ & $A_{1} B_{2}$ & $\mathrm{~A}_{2} \mathrm{~B}_{2}$ \\
\hline
\end{tabular}

Kuantitatif Desain Faktorial $2 \times 2$ learning berbantuan paket program simulasi $P h E T$ dan LKS. Instrumen pengukuran terdiri dari soal kemampuan awal fisika dan prestasi belajar fisika untuk mengukur prestasi belajar fisika siswa materi listrik arus searah.

Teknik analisis data dilakukan pengujian hipotesis dan uji prasyarat analisis yaitu uji normalitas dan uji homogenitas, dilakukan pengujian kesamaan awal dari sampel yang digunakan. Kemudian dilakukan uji hipotesis penelitian dengan Anava Dua Arah (Two-Way Anova).

\section{HASIL DAN PEMBAHASAN Data Kemampuan Awal Siswa}

Tes kemampuan awal dilaksanakan pada awal pembelajaran pada kelas kontrol dan eksperimen. Setelah dilakukan tes kemampuan awal, didapatkan siswa kelompok kemampuan awal tinggi dan rendah. Hasil tes kemampuan awal dapat dilihat pada Gambar 1.

Dari Gambar 1 terlihat bahwa skor ratarata kemampuan awal di kelas eksperimen dan kelas kontrol selisihnya sangat kecil sekali yaitu 3,52 . Hal ini berarti bahwa tingkat kemampuan awal pada kelas eksperimen dan kelas kontrol adalah tersebar merata. Jumlah kemampuan awal tinggi dan rendah pada kelas eksperimen dan kelas kontrol jumlahnya hampir sama dan tersebar merata di dalam masing-masing kelas.

Gambaran perbandingan nilai rata-rata kemampuan awal tinggi dan rendah pada kelas

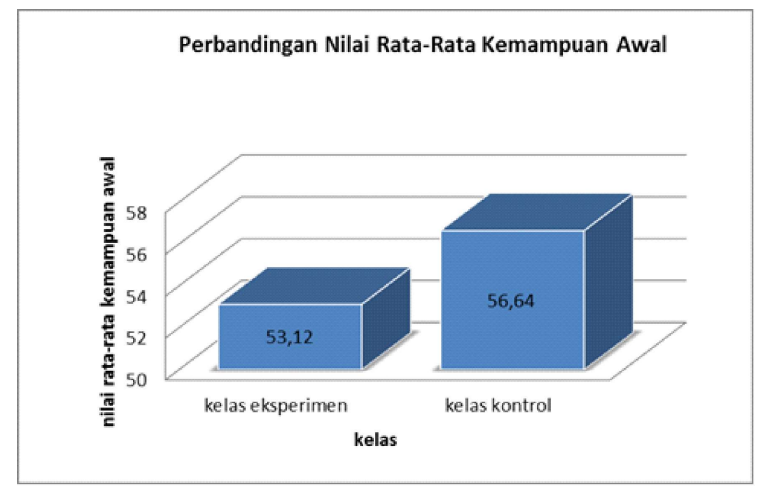

Gambar 1. Perbandingan Nilai Rata-rata Kemampuan Awal Kelas Eksperimen dan Kontrol 
eksperimen dan kontrol dapat dilihat pada Gambar 2.

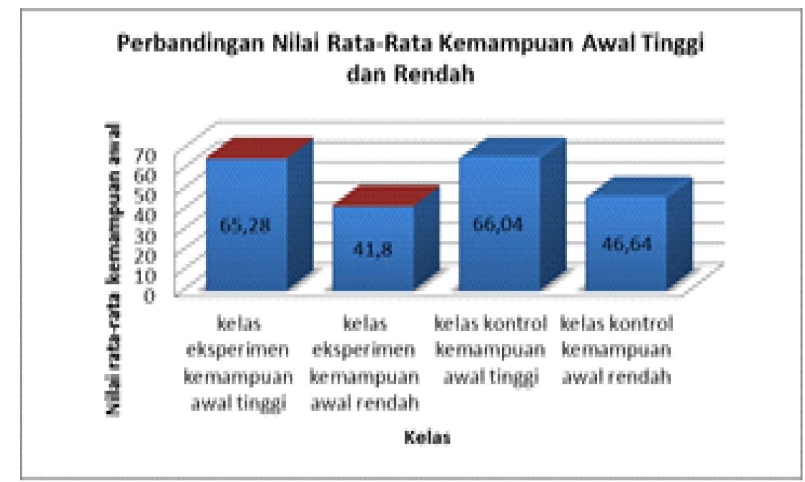

Gambar 2. Perbandingan Nilai Rata-rata Kemampuan Awal Tinggi dan Rendah pada Kelas Eksperimen dan Kontrol

Dari Gambar 2 terlihat bahwa skor ratarata kemampuan awal tinggi dan rendah dari kelas eksperimen dan kelas kontrol memiliki selisih perbedaan yang tidak jauh terhadap masingmasing kelompok. Pada kelompok berkemampuan awal tinggi kelas eksperimen dan kelas kontrol terdapat selisih perbedaan skor rata-rata sebesar 0,76. Hal ini berarti bahwa tingkat kemampuan awal tinggi pada kelas eksperimen dan kelas kontrol adalah tersebar merata. Sedangkan pada kelompok berkemampuan awal rendah kelas eksperimen dan kelas kontrol terdapat selisih perbedaan skor rata-rata sebesar 4,84. Hal ini berarti bahwa tingkat kemampuan awal tinggi pada kelas eksperimen dan kelas kontrol adalah tersebar merata. Sehingga dapat disimpulkan bahwa kemampuan awal siswa tersebar merata di kelas eksperimen dan kelas kontrol.

\section{Data Prestasi Belajar Fisika Siswa}

Tes prestasi belajar fisika dilaksanakan pada akhir pembelajaran pada kelas kontrol dan eksprimen. Hasil tes prestasi belajar dapat dilihat pada Gambar 3.

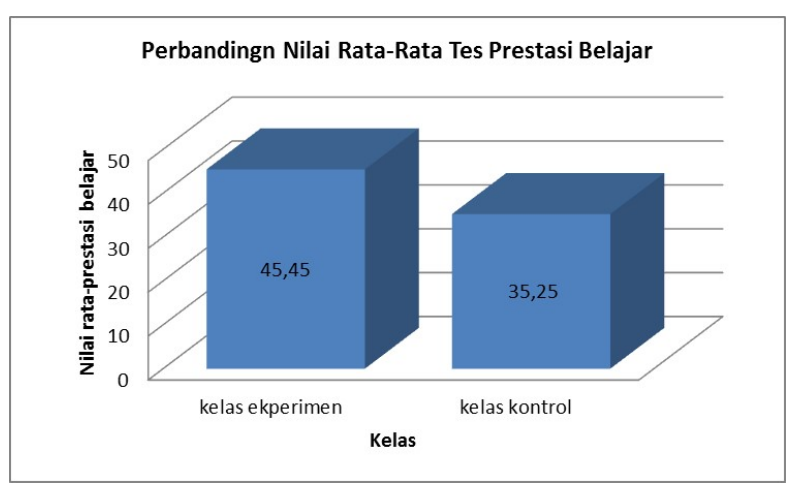

Gambar 3. Perbandingan Nilai Rata-rata Tes Prestasi Belajar Fisika Kelas Eksperimen dan Kontrol

Dari Gambar 3 terlihat bahwa selisih skor rata-rata prestasi belajar kelas eksperimen dan kelas kontrol memiliki selisih perbedaan terhadap masing-masing kelas. Pada kelas eksperimen dan kelas kontrol terdapat selisih perbedaan skor rata-rata sebesar 10,20. Dari data yang diperoleh dapat diartikan bahwa pembelajaran discovery learning berbantuan paket program simulasi PhET pada kelas eksperimen sangat membantu siswa dalam meningkatkan prestasi belajar siswa.

Perbandingan nilai rata-rata prestasi belajar fisika pada kelas eksperimen dan kontrol berdasarkan kemampuan awal dapat dilihat pada Gambar 4.

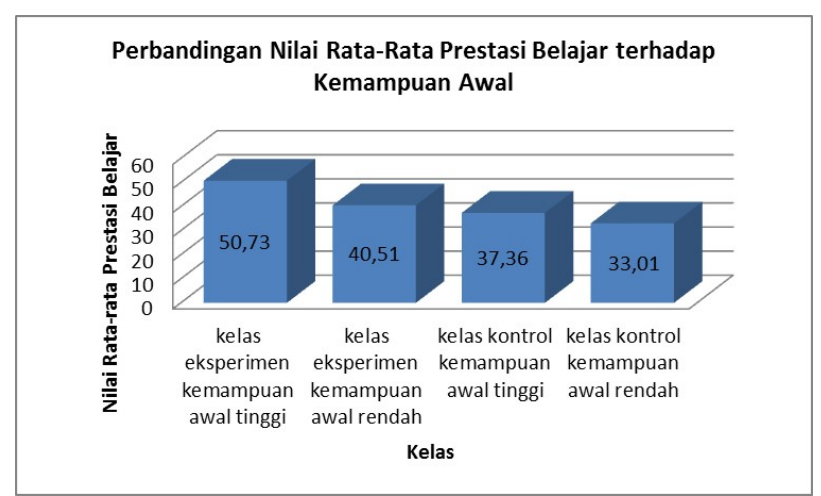

Gambar 4. Perbandingan Nilai Rata-rata Tes Prestasi Belajar Fisika Kelas Eksperimen dan Kontrol Berdasarkan Kemampuan Awal

Dari Gambar 4 terlihat bahwa skor rata-rata berkemampuan awal tinggi dan rendah dari kelas eksperimen dan kelas kontrol memiliki selisih 
perbedaan terhadap masing-masing kelompok. Pada kelompok siswa berkemampuan awal tinggi kelas eksperimen dan kelas kontrol terdapat selisih perbedaan skor rata-rata sebesar 13,37. Sedangkan pada siswa berkemampuan awal rendah terdapat selisih perbedaan sebesar 7,50.

Dari data yang diperoleh dapat diartikan bahwa terjadi peningkatan selisih perbedaan berdasarkan kemampuan awal siswa. Pembelajaran discovery learning berbantuan paket program simulasi PhET pada kelas eksperimen sangat membantu siswa dalam meningkatkan prestasi belajar siswa.

\section{Hasil Uji Hipotesis}

Pengujian hipotesis pada penelitian ini dilakukan dengan analisis varians (Anava) Dua jalur (TwoWay Anova). Sebelum data dianalisis dengan analisis anava dua jalur uang sebelumnya dilakukan diuji asumsi yang mencakup uji normalitas data dan uji homogenitas varian antar kelompok. Hasil analisis data uji hipotesis disajikan pada Tabel 2.

Berdasarkan Tabel 2 dapat ditarik kesimpulan untuk menjawab hipotesis yang telah diajukan. Hasil uji anava dua jalur pada Tabel 2 diperoleh nilai $\mathrm{F}_{\text {hitung }}=17,989$ dengan angka signifikansi sebesar 0,000 lebih kecil dari 0,05. Hasil ini dapat diinterpretasikan bahwa prestasi belajar fisika kelompok siswa yang belajar melalui discovery learning berbantuan paket program simulasi PhET lebih tinggi daripada kelompok siswa yang belajar melalui discovery learning.

\section{PEMBAHASAN \\ Discovery Learning Berbantuan Paket Program Simulasi PhET terhadap Prestasi Belajar Fisika}

Simulasi PhET menekankan hubungan antara fenomena kehidupan nyata dengan ilmu yang mendasari, mendukung pendekatan interaktif dan konstruktivis, memberikan umpan balik, dan menyediakan tempat kerja kreatif (Finkelstein, 2006). Upaya untuk meningkatkan penguasaan konsep fisika dalam proses pembelajaran dapat dibantu dengan penggunaan simulasi PhET (Mubarrok \& Mulyaningsih, 2014). Fenomena fisika dan konsep-konsepnya yang terkait dengan simulasi serta terkait dengan aplikasi keseharian siswa dapat menambah pengetahuan siswa secara visual dan menstimulus lebih banyak siswa untuk mencapai tingkat penguasaan yang tinggi mengenai konsep ilmu fisika (Sunni, dkk., 2013) Simulasi PhET mampu melibatkan siswa dalam eksplorasi seperti ilmuwan dan hasilnya pemahaman siswa terhadap materi lebih besar dan mendalam. Penggunaan simulasi PhET, siswa mampu menjawab hipotesis yang mereka buat, membuat hubungan antar konsep dan menyimpulkan hasil percobaan secara mandiri (Adams, 2010). Podolefsky, dkk. (2013) menginvestigasi penggunaan simulasi $P h E T$ untuk menyelesaikan soal-soal Force Concept Inventory (FCI). Hasilnya siswa mampu menjawab soal-soal FCI dengan baik karena simulasi PhET menampilkan situasi yang mendekati dengan permasalahan kehidupan nyata.

Podolefsky, Perkins, \& Adams (2010) menjelaskan bahwa dengan menggunakan simulasi PhET, siswa mendesain eksperimen secara mandiri, membuat prediksi, dan

Tabel 2. Ringkasan Hasil Analisis Varians Dua Jalur

\begin{tabular}{llll}
\hline Sumber & $d f$ & $F$ & Sig. \\
\hline Kelas Ekperimen-Kontrol & 1 & 35,461 & 0,000 \\
Kelompok Tinggi-Rendah & 1 & 17,293 & 0,000 \\
Kelas Eksperimen-Kontrol*Kelompok Tinggi-Rendah & 1 & 2,789 & 0,002 \\
\hline
\end{tabular}


menggunakan petunjuk yang mendukung ide siswa dalam memecahkan masalah. Siswa juga mampu mengembangkan pemahaman seperti yang dilakukan oleh para ahli dengan cara menggambarkan hubungan sebab-akibat dan menggunakan konsep multi reprensentasi dalam menyelesaikan masalah.

Simulasi PhET juga mampu menghubungkan gagasan yang dimiliki siswa dengan kehidupan nyata yang terjadi dalam kehidupan sehari-hari dan menggunakan fenomena sains dalam simulasi PhET untuk memahami dunia nyata. Hasil penelitian ini didukung oleh temuan-temuan sebelumnya. Prihartiningtyas, dkk. (2013) mengungkapkan bahwa penggunaan simulasi PhET mampu menuntaskan hasil belajar fisika pada materi optik di kelas X SMA Negeri 3 Sragen. Ketuntasan individu untuk kelas yang dibelajarkan menggunakan simulasi PhET sebesar $100 \%$ lebih tinggi daripada ketuntasan individu pada kelas yang dibelajarkan menggunakan kit optik sederhana. Cahyani (2013) menemukan perbandingan gain normalisasi untuk kelompok yang dibelajarkan dengan menggunakan simulasi PhET $(0,74)$ dan kelompok yang dibelajarkan menggunakan Powerpoint $(0,56)$ yaitu bahwa kelompok yang dibelajarkan dengan menggunakan simulasi PhET lebih efektif daripada kelompok yang dibelajarkan menggunakan Powerpoint. Alrsa'i \& Aldhamit (2014) melakukan penelitian di Al-Husain Bin Talal University di Jordan dan hasilnya adalah prestasi belajar siswa yang dibelajarkan menggunakan simulasi PhET berbasis pembelajaran inkuiri lebih tinggi daripada prestasi belajar siswa yang dibelajarkan menggunakan traditional lecture pada materi listrik dan magnet. Rata-rata prestasi belajar siswa yang dibelajarkan menggunakan simulasi PhET sebesar 45,45 dan rata-rata prestasi belajar siswa yang dibelajarkan menggunakan traditional lecture sebesar 35,25. Tambade \& Wagh (2011) menemukan bahwa simulasi komputer adalah cara yang sesuai untuk meningkatkan pemahaman siswa pada materi listrik statis. Hasil penelitian ini menunjukkan bahwa siswa yang dibelajarkan menggunakan simulasi komputer mampu meningkatkan tingkat pemahaman pada materi listrik statis.

Dengan demikian, siswa yang belajar menggunakan discovery learning tanpa simulasi PhET kurang maksimal dalam memahami konsep fisika. Hal ini disebabkan karena discovery learning tidak dapat melingkupi seluruh materi yang dibelajarkan dan membutuhkan persiapan dan proses pembelajaran yang lama. Akibatnya, prestasi belajar fisika rendah.

\section{Discovery Learning Berbantuan Paket Program Simulasi PhET ditinjau dari Kemampuan Awal Tinggi dan Rendah terhadap Prestasi Belajar Fisika}

Kemapuan awal merupakan prasyarat untuk mempelajari pengetahuan yang baru. Semakin baik kemampuan awal yang dimiliki siswa, semakin mempermudah siswa dalam belajar halhal yang baru. Siswa dapat belajar lebih bermakna apabila pembelajarannya mengaitkan antara pengetahuan baru dengan kemampuan awal siswa.

Kemampuan awal merupakan prasyarat terjadinya belajar bermakna. Kemampuan awal dapat dijadikan sebagai pondasi belajar yang dapat membantu pemahaman siswa terhadap suatu konsep. Liu, dkk. (2008) menemukan bahwa siswa yang memiliki kemampuan awal berbeda akan memiliki pendekatan yang berbeda dalam menyelesaikan masalah menggunakan simulasi komputer. Bill (2005) menambahkan bahwa penggunaan simulasi komputer dapat melibatkan siswa dalam menggunakan kemampuan awalnya.

Hasil kajian empirik ini didukung oleh temuan-temuan dari penelitian sebelumnya. McBride, dkk. (2010) melakukan analisis tentang penggunaan kemampuan awal fisika siswa ke dalam konteks yang baru. McBride, dkk. mengungkapkan bahwa penggunaan kemampuan awal dalam proses pembelajaran akan memudahkan siswa memahami konsep serta hubungan antarkonsep. Pritchard, dkk. (2008) menunjukkan bahwa kemampuan awal yang baik akan memberikan keuntungan bagi siswa dalam 
mengikuti posttest. Pritchard, dkk. juga mengungkapkan bahwa tingkat keberhasilan proses pembelajaran tergantung dari kemampuan awal siswa.

Faktor tunggal paling penting yang mempengaruhi pembelajaran adalah apa yang diketahui oleh siswa. Pengetahuan awal merupakan faktor penting bagi siswa dalam proses pembelajaran (Yarden \& Yarden, 2010). Tingkat kemampuan awal siswa harus menjadi tumpuan untuk mengembangkan pembentukan konsep baru pada diri siswa. Siswa membangun pengetahuan baru berdasarkan pengetahuan yang sudah dimiliki. Situasi pembelajaran menjadi optimal karena serasi dengan kemampuan awal siswa.

Kemampuan awal merupakan prasyarat untuk mempelajari konsep yang baru. Kemampuan awal yang dimiliki siswa akan memberikan sumbangan yang besar dalam memprediksi keberhasilan belajar siswa pada masa selanjutnya (Chia \& Chin, 2008). Semakin relevan kemampuan awal yang dimiliki siswa, semakin mempermudah siswa dalam belajar halhal yang baru. Siswa dapat belajar lebih bermakna apabila pembelajarannya mengaitkan antara pengetahuan baru dengan kemampuan awal siswa, karena kemampuan awal yang baik membantu meningkatkan penguasaan konsep oleh siswa.

Kemampuan awal mempengaruhi keberhasilan siswa memberikan interpretasi terhadap apa yang diamati. Kemampuan awal siswa akan membantu mengenali fenomena-fenomena yang diamati dalam kegiatan demonstrasi maupun eksperimen. Miller, dkk. (2013) menyatakan bahwa kemampuan awal siswa akan menentukan keberhasilannya dalam melakukan observasi. Siswa akan mengaitkan hasil observasi dengan pengetahuan yang sudah dimiliki. Penguasaan konsep siswa terbentuk sebagai hasil perpaduan antara hasil pengamatan dengan kemampuan awal tersebut.

Siswa kemampuan awal tinggi yang belajar melalui discovery learning berbantuan paket program simulasi PhET mempelajari terlebih dahulu teori-teori yang ada di buku dan kemudian menggunakan simulasi komputer untuk memprediksi kesesuaian dengan teori-teori yang sudah ada (Liu dkk., 2008). Siswa yang memiliki kemampuan tinggi mampu menganalisis informasi teroganisir yang didapat lebih tepat dan akurat dalam menyelesaikan masalah (Kozma \& Russsel, 2008).

Hasil uji anava perbandingan prestasi belajar siswa berkemampuan awal rendah yang belajar melalui discovery learning berbantuan paket program simulasi PhET lebih tinggi daripada siswa yang belajar melalui pembelajaran discovery learning. Nilai rata-rata prestasi belajar siswa berkemampuan awal rendah yang belajar melalui discovery learning berbantuan paket program simulasi $P h E T$ sebesar 40,51 dan nilai rata-rata prestasi belajar siswa berkemampuan awal rendah yang belajar melalui discovery learning sebesar 33,01.

Siswa berkemampuan awal rendah yang belajar melalui discovery learning berbantuan paket program simulasi PhET dapat mengeksplorasi konsep-konsep sains dengan langkahlangkah mereka sendiri dengan menggunakan simulasi komputer secara efektif (Penuel, dkk., 2006). Wu, dkk. (2001) menambahkan bahwa siswa kemampuan awal rendah mendapatkan bantuan dari siswa yang kemapuan awal tinggi dalam menggunakan simulasi komputer sehingga siswa berkemampuan awal rendah mampu memahami konsep fisika dengan bantuan simulasi PhET dalam kelompoknya. Lazonder, dkk. (2009) melakukan penelitian tentang penggunaan simulasi komputer pada siswa berkemampuan awal rendah dan hasilnya siswa berkemampuan awal rendah mampu memahami materi yang diajarkan dengan bantuan simulasi komputer. Kompleksitas simulasi yang ditampilkan PhET tergolong rendah. Ketika kompleksitas simulasi rendah, maka simulasi itu akan sangat maksimal digunakan oleh siswa yang kemampuan awal rendah (Lee, dkk., 2006).

Dari uraian di atas penulis berpendapat bahwa prestasi belajar fisika kelompok siswa yang belajar melalui discovery learning 
berbantuan paket program simulasi PhET lebih tinggi daripada kelompok siswa yang belajar melalui discovery learning. Prestasi belajar fisika kelompok siswa berkemampuan awal tinggi yang belajar melalui discovery learning berbantuan paket program simulasi $P h E T$ lebih tinggi daripada kelompok siswa berkemampuan awal tinggi yang belajar melalui discovery learning. Sedangkan prestasi belajar fisika kelompok siswa berkemampuan awal rendah yang belajar melalui discovery learning berbantuan paket program simulasi PhET lebih tinggi daripada kelompok siswa berkemampuan awal rendah yang belajar melalui discovery learning.

\section{SIMPULAN DAN SARAN}

\section{Simpulan}

Dari penelitian ini dapat disimpulkan bahwa discovery learning berbantuan paket program simulasi PhET mempengaruhi prestasi belajar siswa dibandingan dengan discovery learning tanpa program simulasi PhET. Pengaruh tersebut yaitu dalam peningkatan prestasi belajar siswa yang menjadi lebih baik. Selain itu, hasil kajian empirik yang didukung oleh temuan-temuan dari penelitian sebelumnya membuktikan bahwa prestasi belajar fisika kelompok siswa berkemampuan awal tinggi yang belajar melalui discovery learning berbantuan paket program simulasi PhET yaitu lebih tinggi daripada kelompok siswa berkemampuan awal tinggi yang belajar melalui discovery learning.

\section{Saran}

Memperhatikan manfaat penggunaan discovery learning berbantuan paket program simulasi PhET pada prestasi siswa, metode pembelajaran ini bisa dikenalkan di sekolah-sekolah dan menjadi alternatif metode pengajaran oleh para guru. digunakan oleh para guru sebagai alternatif dalam. Penelitian lanjutan yang bisa dilakukan adalah menggunakan discovery learning berbantuan paket program simulasi PhET pada materi yang lain.

\section{PUSTAKA ACUAN}

AAPT. 2009. The Role, Education Qualificatios, and Profesional Development of Secondary School Physics Teacher. College Park: The American Assosiation of Physics Teachers on Physics Ellipse.

Adams, W.K. 2010. Student Engagement and Learning with PhET Interactive Simulations. Online First. DOI 10.1393/ncc/i2010-10623-0, diakses 20 Mei 2015.

Adegoke, A.B. 2010. Integrating Animations, Narratives, and Textual Information For Improving Physics Learning. Electronic Journal of Research in Educational Pschology, 8(2) 725-748.

Alfieri, L., Brooks, P.J., \& Aldrich, N.J. 2011. Does Discovery-Based Instruction Enhance Learning? Journal of Educational Psychology. DOI: 10.1037/a0021017.

Alrsa'i, M.S \& Aldhamit, Y.A. 2014. The Effect of Computer Simulation on Al-Husein Bin Talal University Student's Understanding of Elecricity and Magnetism Concepts and their Attitudes towared Physics Learning. International Journal of Educational Research and Technology. 5(1), 54-60. Diakses 20 September 2014.

Amiroh, D. 2014. Pengaruh Visual Scaffolding Berbasis Think Pair Share terhadap Prestasi Belajar Fisika ditinjau dari Pengetahuan Awal Siswa SMAN 9 Malang. Tesis. Malang: Program Pascasarjana Universitas Negeri Malang.

Armstrong, K. \& Retterer, O. 2008. Blogging as L2 writing: A Case Study. AACE Journal, 16(3) 233-251, http://search.ebscohost.com), diakses 20 Oktober 2013.

Asthana. 2010. Multimedia in Education-Introductin, the Elements of, ducational Requirements, Classroom Architecture and Resources, Concersns, http://encyclopedia.jrank.org/ 
articles/pages/6821/Multimedia-in-Education.html, diakses 21 Februari 2014.

Azis, Y.M. 2013. The Effectiveness of Blended Learning, Prior Knowledge to The Understanding Concept in Economics. Educational Research International, 2(2).

Balim, A.G. 2009. The Effects of Discovery Learning on Students' Success and Inquiry Learning Skills. Eurasian Journal of Education Research, http://www.ejer.com.tr/ODOWNLOAD/ pdfler/eng/1177009234.pdf, diakses 17 Maret 2013.

Bill, D.T. 2005. Popular Theory Supporting the Use of Computer Simulation for Experiential Learning. https://fenix.tecnico.ulisboa.pt/downloadFile/3779576747044/article3.pdf, diakses 23 Mei 2014.

Cahyani, M.D. 2013. Pengaruh Media Simulasi PhET terhadap Peningkatan Prestasi Belajar Siswa dalam Konsep Pembiasan Cahaya. http://repository.upi.edu/2339/1/ S IPSE 0901949 Title.pdf, diakses 2 Mei 2014.

Chun-Yen, C. James, P.,B., Ming-Chao, L., Yi-Chun, C. 2007. Assessing Tenth-Grade Students' Problem Solving Ability Online in the Area of Earth sciences. Computers in Human Behavior, 23, 1971-1981, https://pdfs.semanticscholar.org/ad2f/ 9a8fe6a0a8def638542b49a45721beaffb93.pdf., diakses 10 Desember 2013.

Chia, L. \& Chin, C. 2008. Problem Based Learning Tools. The Science Teacher, 44-49.

Chini, J.J., Madsen, A., Gire, E., Rebello, N.S., \& Puntambekar, S. 2012. Exploration of Factors that Affect the Comparative Effectiveness of Physical and Virtual Manipulatives in an Undergraduate laboratory. DOI:10.1103/PhysRevSTPER.8.010113, https:// web.phys.ksu.edu/papers/2012/chini-rebello-prst-per.pdf. diakses 12 juni 2014.

Cohen, M.T. 2008. The Effect of Direct Instruction versus Discovery Learning on the Understanding of Science Lessons by Second Grade Students. NERA Conference Proceeding 2008. http://digitalcommons.uconn.edu/cgi/ viewcontent.cqi?article $=1027 \&$ context $=$ nera 2008. diakses 2 Mei 2014.

Crebert, G., Patrick, C.J., \& Cragnolini, V. 2011. Problem Solving Skills Toolkit. Griffith University, 1-36, https://www.griffith.edu.au/data/assets/pdf file/0008/290717/Problem-solvingskills.pdf, diakses 13 Desember 2014

Finkelstein, N. 2006. High-Tech Tools for Teaching Physics: The Physic Education Technology Project. Marlot Journal of Online Learning and Teaching, 2(3), 110-121, http:// www.colorado.edu/physics/EducationIssues/papers/PhET JOLT.pdf, diakses 12 juni 2013.

Hrastinski, S. \& Monstad, T. 2013. Exploring the Relationship Between the Use of an Interactive Video Website and Organizational Learning. SAGE Journal. DOI: 10.1177/ 1461444813487961, https://uu.divaportal.org/smash/get/diva2:787329/FULLTEXT01.pdf. diakses 10 September 2013.

Indarti, S.A., \& Yogihati, C.I. 2014. Pengaruh Model Discovery Learning terhadap Kemampuan Memecahkan Masalah Siswa Kelas X SMAN 8 Malang, http://fisika.um.ac.id/download/ doc download/441-indarti.html, diakses 4 Mei 2015.

Jong, T.D. \& Joolingen, W.R. 1998. Scientific Discovery Learning with Computer Simulations of Conceptual Domains. Review of Eduacation Research, Summer 1998 vol 68, 2 pp 179201.

Kartikowati, T. 2011. Meningkatkan Keaktifan dan Prestasi Belajar Fisika dengan Pendekatan Pembelajaran Penemuan (discovery) pada Siswa Kelas VIII-2 SMPN 3 Tulungagung. Tesis. 
Malang: Program Pascasarjana Universitas Negeri Malang.

Klahr, D. \& Nigam, M. 2005. The Equivalence of Learning Paths in Early Science Instruction: Effects of Direct Instruction and Discovery learning. Psychological Science, 15(1), 661667, http://www.fi.uu.nl/publicaties/literatuur/ 2004 klahr learning paths early science instruction.pdf, diakses 15 Desember 2016.

Kozma, R.B. \& Russell, J. 2008. Multimedia and Understanding: Expert and Novice Responses to Different Representations of Chemical, http://robertkozma.com/images/ kozma russell jrst article.pdf, diakses 15 Desember 2016.

Lazonder, A.W., Hagemans, M.G., \& Jong, T. 2009. Offering and Discovering Domain Information in Simulation-Based Inquiry Learning. Learning and Instruction, 20, 1-10.

Lee, G., Kwon, J., Park, S.S., \& Kim, J.W. 2005. Development of an Instrument for Measuring Cognitive Conflict in Secondary-Level Science Classes. Journal of Research in Science Teaching, 40 (6) 585-603, ,http://www.rhodes.aegean.gr/ptde/labs/lab-fe/downloads/ articles/ cognitive_conflict.pdf, diakses 20 Pebruari 2014.

Liu, H.C., Andre, T., \& Greenbowe, T. 2008. The Impact of Learner's Prior Knowledge on Their Use of Chemistry Computer Simulations: A Case Study. Journal of Science Education Technology 17, 466-482.

Martinez, G., Naranjo, F. L., Peres, A.L., \& Suero, M.I. 2011. Comparative Study of the Effectiveness of Three Learning Environments: Hyper-realistic Virtual Simulations, Traditional Schematic Simulations and Traditional laboratory. DOI:10.1103/ PhysRevSTPER.7.020111, http://www.kmeljournal.org/ojs/index.php/online publication/ article/viewFile/416/253, diakses 20 Pebruari 2014.

McBride, A.L., Zollman, D., \& Rebello, N.S. 2010. Method for Analyzing Students' Utilization of Prior Physics Learning in New Contexts. Phyisical Review Special Topic-Physics Education Research, 6(2) 1-7.

McKagan, S.B; Perkins, M., Dubson, C., Malley, S., Reid, R., LeMaster., \& Wiemna, C.E. 2008. Developing and Researching PhET Simulation for Teaching Quantum Mechanics. Physics Education Technology Journal. 54(4), 388

Miller, K., Lasry, N., Chu, K., \& Mazur, E. 2013. Role of Physics Lecture Demonstrations in Conceptual Learning. Phyisical Review Special Topic-Physics Education Research, 9(2) 15.

Mubarrok, M.F. \& Mulyaningsih, S. 2014. Penerapan Pembelajaran Fisika pada Materi Cahaya dengan Media PhET Simulations untuk Meningkatkan Pemahaman Konsep Siswa di SMP. Jurnal Inovasi Pendidikan Fisika, 3 (1), 76-80.

Mursalin. 2012. Model Remediasi Miskonsepsi Materi Rangkaian Listrik dengan Pendekatan Simulasi PhET. Jurnal Pendidikan Fisika Indonesia 9 (2013) 1-7. , http:// download.portalgaruda.org/article.php?article $=135453 \&$ val $=5648 \&$ title $=$ MODEL\%20REMEDIASI\%20MISKONSEPSI\%20MATERI\%20RANGKAIAN\% 20LISTRIK\%20DENGAN\%20PENDEKATAN\%20SIMULASI\%20PhET. diakses 17 Mei 2014.

Nisa', C. \& Suliyanah. 2014. Pengaruh Penerapan Pembelajaran Penemuan Terbimbing dengan Mengintegrasikan Keterampilan Proses Sains terhadap Hasil Belajar Siswa SMP Negeri 1 Kamal. Jurnal Inovasi Pendidikan Fisika (JIPF), 3 (1) 30-34, http://ejournal.unesa.ac.id), diakses 3 Mei 2014. 
NSTA. 2005. Position Statement on Scientific Inquiry, http://files.eric.ed.gov/fulltext/ ED489305.pdf, diakses 5 Maret 2014.

Penuel, WR. 2006. Implementation and effects of one-to-one computing initiatives: A research synthesis. Journal of research on technology in education 38 (3), 329-348.

Podolefsky, N. S., Perkins, K. K., \& Adams, W. K. 2010. Factors Promoting Engaged Exploration with Computer Simulations. Physical Review Special Topics-Physics Education Research, 6, 1-11, http://www.unco.edu/nhs/physics/faculty/adams/Research/Adams cv.pdf, diakses 6 Desember 2016.

Podolefsky, N.S., Adams, W.K., \& Wiemen, C.E. 2013. Student Choices when Learning with Computer Simulations. Boulder: University of Colorado.

Podolefsky, N.S., Moore, E.B, \& Perkins, K.K. 2012. Implicit Scaffolding in Interactive Simulations: Design Strategis to Support Multiple Educational Goals. Boulders: University of Colorado http://www.unco.edu/teach/pdf/vitas/AdamsVitae\%20UNCFormat 3 14.pdf, diakses 6 Desember 2016.

Prihatiningtyas, S., Prastowo, T., \& Jatmiko, B. 2013. Implementasi Simulasi PhET dan Kit Sederhana untuk Mengajarkan Keterampilan Psikomotor Siswa pada Pokok Bahasan Alat Optik. Jurnal Pendidikan IPA Indonesia JPII, 2 (1), 18-22, http://jurnal-online.um.ac.id/ data/artikel/artikel99B40F249A0ED6D850A5C3397EF2ECE3.pdf, diakses 6 Desember 2016.

Pritchard, D.E., Lee, Y-J., \& Bao, L. 2008. Mathematical Learning Models That Depend on Prior Knowledge and Instructional Strategies. Phyisical Review Special Topic-Physics Education Research, 4(2) 1-8.

Putrayasa, I., Syahruddin, \& Margunayasa. 2014. Pengaruh Model Pembelajaran Discovery Learning dan Minat Belajar terhadap Hasil Belajar IPA Siswa. Jurnal Mimbar PGSD Universitas Pendidikan Ganesha, 2(1), http://ejournal.undiksha.ac.id/index.php/JJPGSD/ article/download/3087/2561, diakses 3 Maret 2015.

Rahma, A.A. 2013. Pengaruh Model Siklus Belajar Berbantuan Mind Map Terhadap Prestasi Belajar Fisika ditinjau dari Kinerja Laboratorium Siswa Kelas VIII SMP Negeri 1 Rejoso Kabupaten Pasuruan. Tesis. Malang: Program Pascasarjana Universitas Negeri Malang.

Rohim, F., Susanto, H., \& Ellianawati. 2012. Penerapan Model Discovery Terbimbing pada Pembelajaran Fisika untuk Meningkatkan Kemampuan Berpikir Kreatif. Unnes Physics Education Journal. 1(1) 1-5, ,http://journal.unnes.ac.id/artikel sju/pdf/upej/775/800), diakses 6 Desember 2016.

Sadaghiani, H. 2011. Using Multimedia Learning Modules in a hybrid-online course in electricity and magnetism. American Physical Society's Journal. DOI: 10.1103/ PhysRevSTPER.7.010102.

Schunk, D.H. 2008. Learning Theories: An Education perspective. NY: Pearson.

Squire, K., \& Dikkers, S. 2012. Amplifications of learning: Use of Mobile Media Devices Among youth. SAGE journal. DOI: 10.1177/1354856511429646 http://files.eric.ed.gov/fulltext/ EJ1079080.pdf., diakses 10 September 2013.

Sunni, M.A. 2013. Pengaruh Pembelajaran Problem Solving Berbantuan PhET terhadap Penguasaan Konsep Fisika dan Kemampuan Berpikir Kritis Siswa Kelas X SMAN 8 Mataram. Tesis. Malang: Program Pascasarjana Universitas Negeri Malang. 
Swaak, J., Jong, T., \& Joolingen, W.R. 2004. The Effects of Discovery Learning and Expository Instruction on the Acquisition of Eefinitional and Intuitive Knowledge. Journal of Computer Assisted Learning. 20, 225-234.

Tambade, P.S. \& Wagh, B.G. 2011. Assessing the Effectiveness of Computer Assisted Instructions in Physics at Undergraduate Level. Eurasian Journal of Physics Eduacation, 3(2) 127-136, http://www.eurasianjournals.com/index.php/ejpce. diakses 23 Juli 2014.

Wenning, C.J. 2011. The Levels of Inquiry Model of Science Teaching. Journal of Physics Teacher Education, 6(2)11-16, http://www2.phy.ilstu.edu/pte/publications/LOI-modelof-science-teaching.pdf, diakses 20 Februari 2014.

Wu, H.K., Krajcik, J.S., \& Soloway, E. 2001. Promoting Understanding of Chemical Representations: Students' Use of a Visualization Tool in the Classroom. Journal of Research in Science Teaching. 38(7) 821-842, diakses 3 Maret 2014.

Yarden, H. \& Yarden, A. 2010. Learning Using Dynamic and Static Visualizations: Students' Comprehension, Prior Knowledge and Conceptual Status of a Biotechnological Method. Res Science Education, 40, 375-402, diakses 2 Mei 2014. 